\title{
Applying Universal Instructional Design to Course Websites by Using Course Evaluations
}

\author{
Irene Carter, Donald Leslie, \& Denise Kwan \\ University of Windsor
}

The authors explore their use of learner-centred teaching strategies and Universal Instructional Design (UID) on course websites. UID is based on universal design, the design of products and environments intended to be usable by all people to the greatest extent possible (Burgstahler \& Cory, 2008). UID applies universal design to instructional products and environments, including course websites. Seeking to assess and improve course website accessibility, faculty aimed to consider to what extent they employ UID as a means to promote inclusive practices and greater accessibility. Through the University of Windsor's university-wide learning management system (CLEW) Learning Community, faculty administered teaching evaluations to students in eight undergraduate courses. Although the evaluations indicated students considered website course delivery involved a fairly high level of accessibility, future studies are required to determine to what extent course websites reflect UID-based teaching strategies that promote accessibility.

\section{Introduction}

$\mathrm{F}$ ichten et al. (2003) estimate the number of North American post-secondary students with a disability ranges from $5 \%$ to $11 \%$ (p.75). Bryson (2003) illustrates that in a class of 50 students, there will likely be four with auditory learning disabilities, one to two with visual/organizational visual disabilities, one to two with visual or hearing impairments, one with lower ability, two to four with mental health issues, two to four with attention deficits, one to three with medical conditions, one to three with mobility limitations, and three to eight who are underprepared. This illustration of a class of 50 students indicates that the number of students requiring diverse methods of teaching and learning ranges from 32\% to 58\%. In Ontario, the Accessibility for Ontarians with Disabilities Act (2005) supports the plan to achieve accessibility by 2025 by developing, setting up, and enforcing accessibility standards that include services such as education. Accessibility for all post-secondary students results in increased rates of student recruitment, engagement, and retention (Ministry of Community and Social Services, 
2008). In this paper, we reinforce how important accessibility is in a post-secondary Ontario setting, specifically seeking to outline and evaluate guidelines and strategies that instructors can use, effectively, to create course websites that are accessible to all.

\section{Learner-Centred, Teaching Principles and Universal Design}

A learner-centred approach aims to meet students' learning needs based on the perspective of the student (Hubball, Gold, Mighty, \& Britnell, 2007). Instructors share decisions about learning with students, allowing them some control over their learning (Weiner, 2002). Instructors aim to provide clear learning expectations, help students make use of their knowledge, and promote principles of accessibility while still upholding academic rigor. The Seven Principles for Good Practice in Undergraduate Education represents widely recognized, evidencebased teaching practices (Chickering \& Ehrmann, 1996; Chickering \& Gamson, 1987). The principles include encouraging student-faculty contact, active listening, stressing time on task, providing prompt feedback, communicating high expectations, developing reciprocity and cooperation among students, and respecting diverse talents and ways of learning (Chickering \& Gamson, 1987). In a learner-centred environment, these principles apply to post-secondary websites and classrooms.

Instructional methods that pose barriers for diverse learners lead to poor outcomes, including limited understanding of curricular material, inability to engage, frustration, lower grades, inability to complete the course, and lack of success in the course overall (Keeler \& Horney, 2007). Traditionally, students with special needs received retrofitted instruction designed specifically for them, and often inconsistent with the content and rigor of the general education curriculum (Boone \& Higgins, 2007, as cited in Sapp, 2009). The educational standards movement and increasing student diversity served to promote educational improvement and reform. Universal design, and its application to teaching and learning, Universal Instructional Design (UID), surfaced as a necessary approach (Bryans Bongey, Cizadlo, \& Kalnbach, 2010).

Universal design is the design of products and environments intended to be usable by all people to the greatest extent possible without the need for adaptation or specialized design (Center for Universal Design, 2011). UID is the application of universal design to instructional products and environments that goes beyond the traditional approach of making accommodations and adjustments for individual learners (Burgstahler \& Cory, 2008). The principles of UID recommend that instructors plan for equitable use, flexibility in use, simple and intuitive use, perceptible information, a tolerance for error built in, and low physical effort. Additionally, instructors are to consider size and space for suitable use, create a community of learners, and create an inclusive climate. These principles promote the consideration and potential needs of all learners while removing barriers and upholding academic rigor (Burgstahler \& Cory, 2008; Coomber, 2007).

UID creates physical, social, and learning environments to meet the needs of a diverse population (Curry, Cohen, \& Lightbody, 2006). This framework guides the design of seamless education for the widest number of learners, thus minimizing the need for individual variations (Burgstahler \& Cory, 2008; Hitchcock \& Stahl, 2003). UID supports learning by providing multiple and flexible methods of presentation and strategic learning; by providing various means of expression and apprenticeship; and by providing many choices for engagement (Hall, Strangman, \& Meyer, 2009; Hitchcock \& Stahl, 2003). UID allows learners to experience minimal barriers and to maximize their access to course and instructional materials (Hall et al., 2009), presenting clearer expectations and unambiguous instructions. Thus, UID involves effective teaching techniques, inclusiveness, accessibility practices, and application of technology (Bryson, 2003).

\section{Universal Instructional Design, Course Websites, and Accessibility}

Technology performs an increasingly widespread 
and invaluable role as a cost-effective way to advance the Seven Principles for Good Practice in Undergraduate Education (Chickering \& Ehrmann, 1996) with its potential for flexible, encouraging, and adjustable experiences (Hitchcock \& Stahl, 2003). The increasing demand for accessible postsecondary websites encourages instructors to use UID to ease understanding among diverse learners. Current learning environments call for both assistive technologies and UID, because only together is there acceptable accessibility and support to promote learning for all (Hitchcock \& Stahl, 2003).

Elias (2010) tailored eight principles of UID relevant to course websites. He ensures equitable use with useful and accessible instructional materials available to all learners in identical or equivalent formats. Providing learners with choices in methods of use upholds flexible use by considering individual learners' abilities, preferences, schedules, and levels of connectivity. A course design that everyone understands meets the principle of being simple and intuitive. Effectively communicating necessary information to all learners ensures information is perceptible. Tolerance for error is obvious when adverse effects of learners' accidental or unintended actions are minimized. Efficient, comfortable websites result in low physical and technical effort, minimizing physical or mental fatigue. A web-based community of learners and supports promotes a learning environment where there is interaction between students, faculty, and administrative services. Also, positive instructional climate is created when students receive welcoming instructor feedback. These principles are applicable to components of course websites which include course notes, syllabi, schedules, access to grade information, links to added resources, assessments, feedback, chat rooms, discussion boards, and virtual office hours (Bryans Bongey et al., 2010; Hitchcock \& Stahl, 2003; Keeler \& Horney, 2007; Sapp, 2009).

Desire2Learn (2011), Blackboard Learn (2011), Sakai (2011), and the Collaboration and Learning Environment Windsor (Centre for Teaching and Learning, 2011) are learning management systems (LMS) that provide examples of website environments to which instructors can apply pedagogical implementations such as
UID. Desire2Learn (2011) focuses on research, development, service, and support, and aims to ensure their system and tools are user-friendly and easy to navigate. Blackboard Learn (2011) focuses on fostering student engagement, supporting educational efficiency, delivering open and extensible learning, and connecting student instruction with institutional improvement. Sakai, a learning management system used by over 350 institutions (Sakai, 2011), provides open-source software to support users in teaching, learning, and research.

Based on the Sakai learning management system platform, the Collaboration and Learning Environment Windsor (CLEW) is the University of Windsor's customized learning management system (Centre for Teaching and Learning, 2012). Some features of CLEW that instructors use include the ability to post lecture notes or PowerPoint presentations on-line, make announcements, and guide learning through online lessons. CLEW also creates opportunities for discussing group work in discussion forums, accepting assignments on-line, forwarding confidential feedback and grades, and providing instructors with training opportunities.

The web provides a growing source for course resources and tools to improve students' learning experiences (Leung \& Ivy, 2003). Assistive technology helps individuals with disabilities to perform functions otherwise difficult or impossible, and includes computer hardware and software as well as mobility devices, such as walkers and wheelchairs (Access IT, 2012). The Web Accessibility Initiative (WAI, 2011) is sponsored by government and industry. The WAI supports agencies such as Canada's Assistive Devices Industry Office (Canadian Assistive Devices Industry - Information Sources, 2011) that focus on offering support to persons with disabilities. The WAI develops strategies, guidelines and resources to make the Web more accessible; and it works with organizations around the world, promoting core evaluation tools for accessibility, conducting education and outreach, and coordinating research and development. Additionally, the Web Content Accessibility Guidelines 2.0 (WCAG, 2011) support accessible web content by providing information to instructors and others who are striving to apply UID 
effectively to web-based course instructional materials used on an LMS (Caldwell, Cooper, Guarino Reid, \& Vanderheiden, 2008; Hitchcock \& Stahl, 2003).

\section{Teaching Evaluation of Course Websites}

To gain insight into the accessibility-related strengths and weaknesses of CLEW, the authors conducted an evaluation of undergraduate students' views about CLEW's accessibility. In the 2010 fall semester at the University of Windsor, approximately 350 undergraduate students from eight courses, six in social work and two in disability studies, answered 12 additional course evaluation questions. These questions reflected UID on-line learning recommendations, best practices associated with UID and accessibility standards as outlined by the AODA (2005). The rating scale choices were: (1) extremely poor, (2) very poor, (3) poor, (4) adequate, (5) good, (6) very good, (7) outstanding, and (0) not applicable. The questions supplemented the existing, end-of-term, course evaluations. Overall, scores averaged a rating of 5 out of 7 or better (Table 1).

The responses supported instructors who used UID principles in developing their course websites. Questions that directly referred to the accessibility and usefulness of CLEW received the highest ratings. The high ratings for questions 4, 6, and 8 showed CLEW complies with accessibility guidelines; however, it remains unclear whether the high evaluation of CLEW regarding accessibility suggests a learning system that performs well overall within a UID framework. Weaknesses of this learning system may exist, and may be attributable to the learning system, the instructor, or both. The lowest ratings were for questions 3,11 , and 12 , suggesting such problems as communication barriers, difficulty of use, lack of adaptability of technology, and limited usefulness.

The combined ratings were high ( 5 or higher), which reflected better than anticipated outcomes. However, knowledge of, and sensitivity towards, accessibility concerns may be more present in social work or disability studies students who answered the questions. The question remains whether students from other disciplines or diverse course designs might evaluate the accessibility of their course web sites differently. Future evaluations should seek responses about the accessibility of course web sites from students in other disciplines. Also, future studies should consider assessment for each course in regard to the Seven Principles for Good Practice in Undergraduate Education and the eight principles of UID. Moreover, this evaluation did not compare the ratings between students with disabilities and students without disabilities. Future studies should also seek responses from students with disabilities about the accessibility of course websites.

There were limitations to the study. Students' evaluations might have rated their instructors rather than the accessibility of the learning system. The presence of outliers influenced the rating averages. For example, in question three, where students in course C selected "not applicable," the instructor may not have used the course website to communicate with students. Moreover, in question 12, the "very poor" outcome was attributable to one response. Students did not consistently answer all twelve questions, suggesting future studies should better manage low response rates. The evaluation instrument needs improvement; for example, several questions contain more than one idea, presenting opportunities for misinterpretation by respondents and by analysts interpreting the results. Those questions should be split into multiple questions that highlight only one idea at a time. Some questions appeared to evaluate the same underlying idea, allowing for multiple interpretations, and requiring rewording to highlight their differences. Future studies should also consider the use of focus groups that could help to further develop and revise evaluation questions.

\section{Conclusion}

Our findings from this preliminary study indicated high student ratings for the accessibility and usefulness of the course website. Further research is needed to determine the extent that the results are attributable to the learning management system (L. 
TABLE 1

Student Evaluation of Course Web Site Results

\section{Courses $\mathrm{A}$ to $\mathrm{H}$}

\section{Questions}

1. How well did the web site postings facilitate your learning?

2. How well was the course material presented on the course web site in an organized, well-planned manner?

3. How well did the instructor communicate clearly and effectively on the course web site?

4. How 'readable' were the course web pages (i.e. font, font size, use of white space/web design, etc...)?

5. How responsive was the instructor to difficulties you may have experienced with the web site?

6. How well was the course web site organized to promote your learning?

7. How well did the web site explain content clearly?

8. How well were you able to easily navigate the web site to find information about the course?

9. How well did the web site provide clear guidelines and expectations for assignments?

10. How well were course materials posted in a timely fashion?

11. How well did the web site accommodate different technical systems through the use of multiple formats?

12. The value of the overall course web site learning experience was...

$\begin{array}{llllllllll}\text { A } & B & C & D & E & F & G & H & A^{*}\end{array}$

$\begin{array}{lllllllll}5.3 & 5.3 & 6.7 & 6 & 4.6 & 5.7 & 6.1 & 5.6 & 5.7\end{array}$

$\begin{array}{lllllllll}5.2 & 5.5 & 6.5 & 6 & 5.1 & 5.9 & 6 & 5.8 & 5.8\end{array}$

$\begin{array}{lllllllll}5.5 & 5.6 & 0 & 5.3 & 5 & 6.1 & 5.8 & 5.7 & 4.9\end{array}$

$\begin{array}{lllllllll}5.5 & 5.6 & 6.9 & 6.2 & 5.2 & 6 & 6.1 & 5.8 & 5.9\end{array}$

$\begin{array}{lllllllll}5.8 & 5.6 & 5.9 & 5.4 & 5 & 6 & 6 & 5.7 & 5.7\end{array}$

$\begin{array}{lllllllll}5.2 & 5.4 & 7 & 6.7 & 4.9 & 5.9 & 6 & 5.7 & 5.9\end{array}$

$\begin{array}{lllllllll}5.5 & 5.5 & 6.6 & 6.1 & 4.9 & 6 & 6 & 5.7 & 5.8\end{array}$

$\begin{array}{lllllllll}6 & 5.9 & 5.8 & 5.9 & 5.2 & 6.2 & 6.3 & 5.9 & 5.9\end{array}$ $\begin{array}{lllllllll}5.3 & 5.4 & 5.4 & 5.6 & 5.4 & 6 & 5.9 & 5.9 & 5.6\end{array}$

$\begin{array}{lllllllll}5.8 & 5.5 & 6 & 5.6 & 5.4 & 6.4 & 6.3 & 6.1 & 5.9\end{array}$ $\begin{array}{lllllllll}5.2 & 5.6 & 4.3 & 4.8 & 4.7 & 6 & 6 & 5.6 & 5.3\end{array}$ $\begin{array}{lllllllll}5.3 & 5.4 & 1 & 6 & 4.7 & 6.2 & 6.1 & 5.9 & 5.1\end{array}$

*Average 
Stolarchuk \& G. Fawcett, personal communication, September 23, 2011). Factors that scored lower, such as communication barriers, difficulty of use, and adaptability of technology also require further investigation. Questions to consider in such future research include: (a) How much of a barrier is an LMS that implements UID in the course design? and (b) How much of an effort is required in integrating UID into the online course design?

\section{References}

Accessibility for Ontarians with Disabilities Act [AODA]. (2011). S.O. 2005, chapter 11. Retrieved from http://www.aoda.ca/?page_ id $=8$

AccessIT. (2012). What is assistive technology? The National Center on Accessible Information Technology in Education, University of Washington. Retrieved from http://www. washington.edu/accessit/articles?109

Blackboard Learn. (2011). Accessibility. Retrieved from http://www.blackboard.com/ Platforms/Learn/Resources/Accessibility.aspx

Bryans Bongey, S., Cizadlo, G., \& Kalnbach, L. (2010). Blended solutions: Using a supplemental online course site to deliver universal design for learning (UDL). CampusWide Information Systems, 27(1), 4-16.

Bryson, J. (2003). Universal instructional design in postsecondarysettings: An implementationguide. Retrieved from http://www.ontla.on.ca/ library/repository/ mon/8000/243213.pdf

Burgstahler, S.E., \& Cory, R C. (Eds.). (2008). Universal design in higher education: From principles to practice. Cambridge, MA: Harvard Education Press.

Caldwell, B., Cooper, M., Guarino Reid, L., \& Vanderheiden, G. (Eds.). (2008). Web content accessibility guidelines 2.0. Retrieved from http://www.w3.org/TR/WCAG20/

Canadian Assistive Devices Industry - Information Sources. (2011). Assistive technology links (AT-Links). Retrieved from http://www.atlinks.gc.ca/as/

Centre for Teaching and Learning. (2012). Learning technologies. What's CLEW. Retrieved from http://www.uwindsor.ca/ctl/clewctl

Center for Universal Design. (2011). Retrieved from http://www.ncsu.edu/project/designprojects/udi/

Chickering, A.W. \& Ehrmann, S.C. (1996). Implementing the seven principles: Technology as a lever. Retrieved May 9, 2009, from http:// www.tltgroup.org/programs/seven.html

Chickering, A.W. \& Gamson, Z.F. (1987). Seven principles for good practice in undergraduate education. Retrieved May 9, 2009 from http://learningcommons.evergreen.edu /pdf/ fall1987.pdf

Coomber, S.A. (2007). Students with disabilities: Post-secondary voices and universal design for learning. Doctoral dissertation retrieved from http://ir.lib.sfu.ca/handle/1892/3463

Curry, C., Cohen, L., \& Lightbody, N. (2006). Universal design in science learning. The Science Teacher, 73(3), p. 32-37.

Desire2Learn. (2011). Accessibility. Retrieved from http://www.desire2learn.com/access/

Elias, T. (2010). Universal instructional design principles for Moodle. International Review of Research in Open and Distance Learning, 11(2), 110-124.

Fichten, C.S., Asuncion, J.V., Barile, M., Robillar, C., Fossey, M.E., \& Lamb, D. (2003). Canadian 
postsecondary students with disabilities: Where are they? The Canadian Journal of Higher Education, 33(3), 71-114.

Hall, T., Strangman, N., \& Meyer, A. (2009). Differentiated instruction and implications for UDL implementation: Effective classroom practices report. National Center on Accessing the General Curriculum. Retrieved from http://aim.cast.org/learn/ historyarchive/ backgroundpapers/differentiated_ instruction_udl

Hitchcock, C. \& Stahl, S. (2003). Assistive technology, universal design for learning: Improved learning opportunities. Journal of Special Education Technology, 18(4), 45-52.

Hubball, H., Gold, N., Mighty, J., \& Britnell, J. (2007). Supporting the implementation of externally generated learning outcomes and learning-centred curriculum development. New Directions for Teaching and Learning, (112), 93-105.

Keeler, C.G., \& Horney, M. (2007). Online course designs: Are special needs being met? The American Journal of Distance Education, 21(2), 61-75.

Leung, Y.F. \& Ivy, M.I. (2003). How useful are course websites? A study of students' perceptions. Journal of Hospitality, Sport, Leisure and Tourism Education, 2(2).

Ministry of Community and Social Services. (2008). Understanding accessibility. Retrieved from http://www.mcss.gov.on.ca/en/ mcss/programs/accessibility/understand_ accessibility/index.aspx

Sakai. (2011). The Sakai community. Retrieved from http://sakaiproject.org/community-home

Sapp, W. (2009). Universal design: Online educational media for students with disabilities. Journal of Visual Impairment \& Blindness, 103(8), p. 495-500.

Web Accessibility Initiative [WAI]. (2011). WAI mission and organization. Retrieved from http://www.w3.org/WAI/about.html

Web Content Accessibility Guidelines [WCAG]. (2011). Web content accessibility guidelines overview. Retrieved from http://www.w3.org/ WAI/intro/wcag

Weiner, M. (2002). Learner-centered teaching: Five key changes to practice. San Francisco, CA: Jossey-Bass.

\section{Biographies}

Irene Carter is an Associate Professor at the School of Social Work in the University of Windsor. Dr. Carter's interests focus on curriculum development, disability studies, clinical practice, and social support for persons with intellectual and developmental disabilities.

Donald Leslie is a Professor and Bachelor of Social Work Coordinator in the School of Social Work at the University of Windsor. Dr. Leslie is involved in non-profit organization and board governance, workplace accommodation of persons with disabilities, disability studies, and is a 2010 recipient of the Ontario Confederation of University Faculty Associations (OCUFA) Teaching Award.

Denise Kwan is a Masters of Social Work graduate, University of Windsor. 